\title{
Prevalence and associated factors of computer
} vision syndrome among bank workers in Gondar City, northwest Ethiopia, 2015

This article was published in the following Dove Press journal:

Clinical Optometry

10 April 2017

Number of times this article has been viewed

\section{Natnael Lakachew Assefa \\ Dawit Zenebe \\ Weldemichael \\ Haile Woretaw Alemu \\ Dereje Hayilu Anbesse}

Department of Optometry, College of Medicine and Health Sciences, University of Gondar, Gondar, Ethiopia
Correspondence: Natnael Lakachew Assefa

Department of Optometry, College of Medicine and Health Sciences, University of Gondar, PO Box 196,

Gondar, Ethiopia

Tel +25 I 910088903

Email natnaell@yahoo.com
Introduction: Use of computers is generally encouraged; this is to keep up with the fast-moving world of technology, research and science. Extensive use of computers will result in computer vision syndrome (CVS), and the prevalence is increased dramatically. The main objective of the study was to assess the prevalence and associated factors of CVS among bank workers in Gondar city, northwest Ethiopia.

Methods: A cross-sectional institution-based study was conducted among computer-using bank workers in Gondar city from April to June, 2015. Data were collected through structured questionnaires and observations with checklists, entered with Epi Info ${ }^{\mathrm{TM}} 7$ and analyzed by Statistical Package for the Social Sciences (SPSS) version 20. Descriptive statistics and logistic regression were carried out to compute the different rates, proportion and relevant associations. Results: Among the total 304 computer-using bank workers, the prevalence of CVS was $73 \%$ (95\% confidence interval $[\mathrm{CI}]=68.04,78.02)$. Blurred vision $(42.4 \%)$, headache $(23.0 \%)$ and redness $(23.0 \%)$ were the most experienced symptoms. Inappropriate sitting position was 2.3 times (adjusted odds ratio $[\mathrm{AOR}]=2.33 ; 95 \% \mathrm{CI}=1.27,4.28$ ) more likely to be associated with CVS when compared with appropriate sitting position. Those working on the computer for more than 20 minutes without break were nearly 2 times ( $\mathrm{AOR}=1.93 ; 95 \% \mathrm{CI}=1.11,3.35$ ) more likely to have suffered from CVS when compared with those taking break within 20 minutes, and those wearing eye glasses were 3 times $(\mathrm{AOR}=3.19 ; 95 \% \mathrm{CI}=1.07,9.51)$ more likely to suffer from CVS when compared with those not wearing glasses.

Conclusion: About three-fourths of computer-using bank workers suffered from CVS with the most experienced symptoms being blurred vision, headache and redness of eyes. In appropriate sitting position, working on the computer without a break for more than 20 minutes and wearing eye glasses were independently associated with CVS.

Keywords: computer vision syndrome, computer users, bank workers, Gondar

\section{Introduction}

Globally, personal computers are one of the most common office tools. Using computers had become a 21 st century necessity. The use of computers in all institutions, colleges, universities and homes has made life easier and has increased output tremendously. ${ }^{1,2}$

However, their usage, even for 3 hours/day, has led to a health risk of developing computer vision syndrome (CVS), low-back pain, tension headaches and psychosocial stress. $^{3}$ Ocular complaints of computer users have been grouped together and collectively termed as CVS. ${ }^{4}$

The American Optometric Association defines CVS as a complex of eye and vision problems related to the activities that stress the near vision and that are experienced in 
relation to, or during, the use of the computer. It is characterized by visual symptoms that result from interaction with computer display or its environment. ${ }^{5}$

CVS is an umbrella term that covers numerous eye- and environment-related conditions that occur when the viewing demands of the task exceed the visual abilities of the user, leading to inability to focus properly on computer images. The eyes cannot remain focused on the pixel-generated images on a computer screen, and as such, the eyes must focus and refocus thousands of times per day while viewing the screen. ${ }^{6}$

CVS can also be presented with asthenopic symptoms of eyes, such as eye strain, irritation, redness, fatigue, headaches, burning sensation, glare sensitivity, double vision and periodic blurring of near and distant vision. ${ }^{7}$

Factors contributing to CVS were generally classified as personal factors - poor sitting position, improper viewing distances, improper viewing angle, ocular diseases, medical diseases and aging and environment; and computer factors - poor lighting, imbalance of light between the computer screen and the surrounding, poor resolution, poor contrast, glare of the display and slow refresh rate. ${ }^{8}$

The discomfort associated with computer usage has not yet been proven to result in permanent damage, but may cause a reduction in work accuracy. This can reduce productivity by as much as $40 \% .{ }^{9}$ Use of computers is generally encouraged; this is to keep up with the fast-moving world of technology, research and science. Researchers have come to an agreement that this could actually be harmful, if not properly managed for future generation. ${ }^{10}$ Today, in virtually every corporate cubicle and backroom office, on the desks of every bank workers, sits a computer that allows writing, designing, computing and communicating faster than ever before. More time is spent working on a computer; the knowledge of using the computer and the computer screen by itself has a great contribution for the problems related with the use of computers. It is known that CVS is a worldwide problem, but in Ethiopia, there is limited evidence to prove the magnitude and risk of the problem. Accordingly, the study was conducted in Gondar city among bank workers who spent most of their time on computer, to know the magnitude and risk factors of computer-related vision problems. The study conducted in this area will show the magnitude and predictors of CVS, and any technology managers and eye care professionals can use this research for planning of reducing the risk of CVS. Moreover, the study will be a baseline resource for other researchers researching on computer vision-related problems.

\section{Materials and methods}

An institution-based cross-sectional study was conducted from May 5 to June 15, 2015 in Gondar city, northwest Ethiopia. Gondar city is located $\sim 750 \mathrm{~km}$ northwest from the national capital, Addis Ababa and $\sim 180 \mathrm{~km}$ from Bahir Dar city, the regional capital of the Amhara. Gondar is one of the ancient and largely populated cities of the country, having a population of $\sim 303,815$. It has a latitude and longitude of $12^{\circ} 36^{\prime} \mathrm{N}$ and $37^{\circ} 28^{\prime} \mathrm{E}$, respectively, with an elevation of 2133 $\mathrm{m}$ above sea level. ${ }^{11}$ In Gondar city, nowadays, there are $\sim 33$ governmental and nongovernmental banks serving the community. All computer-using bank workers were included in the study except bank workers who had ocular diseases, such as acute, chronic, infective conjunctivitis, any specific eyelid disorders, uncorrected refractive error and other binocular vision problems.

The sample size was determined by using the single population proportion and correction formula because the population was $<10,000$ (which was 308) with the assumption of the level of significance $(\alpha)=5 \%$ (with confidence level of $95 \%$ ), marginal error $\mathrm{w}=5 \%$ and $P=0.739$ (previous study on secretaries and data processors at Gondar University). ${ }^{12}$ The $Z$ value was 1.96 ( $\mathrm{n}=$ sample size, $\mathrm{P}=$ proportion and $\mathrm{w}=$ marginal error), which was 172 bank workers. But in this study, computer users who were not eligible for the study were excluded, and for the confidence of the research power, all computer-using bank workers $(n=308)$ were the final sample size.

Appropriate sitting position - The face of the operator just in level to the computer screen. ${ }^{13}$

Bank workers - Professionals who work on government and private banks.

Computer user - Bank workers who use desktop or laptop single-monitor computer devices for their daily work at the bank arena.

Computer vision syndrome - At least one of the asthenopic symptoms of eyestrain, eye fatigue, blurred vision, headache, dry eye, watery eye, blurred vision, double vision, irritation and burning sensation of the eyes that occur as a result of computer use. ${ }^{14}$

Pretested structured questionnaire (Figure S2) was prepared in English language and translated into Amharic language (working language) for obtaining information about sociodemographic characteristic and personal factors for CVS and then translated back into English language for data entry and analysis. Four data collectors (optometrists) were involved in the data collection procedure. Face-to-face interview using pretested standardized questionnaires and direct observations 
with checklist was conducted to measure personal and environmental factors by an optometrist. Snellen visual acuity card and pinhole for visual acuity measurement, retinoscope for refraction, torch and magnifying loop for ocular segment examination and viewing distance measurement meter were used for clinical evaluations. There were an optometrist supervisor and principal investigator during data collection. Data were entered using Epi Info ${ }^{\mathrm{TM}} 7$ and exported and analyzed by using Statistical Package for the Social Sciences (SPSS) version 20. Descriptive statistic and logistic regression was carried out to compute the different rates, proportions and relevant associations with $95 \%$ confidence interval (CI).

Before conducting the study, ethical clearance was obtained from University of Gondar, College of Medicine and Health Sciences, School of Medicine Ethical Review Committee. Oral consent of each participant was taken after explaining the purpose of the study. Confidentiality of the information was maintained thoroughly by excluding names as identification in the questionnaire and keeping their privacy during data collection, and also individual results were kept secure by locking.

\section{Results}

A total of 304 computer-using bank workers were included in the study with a response rate of $98.2 \%$. From the study participants, $198(65.1 \%)$ were men. The mean age of study participants was $28.29( \pm 4.66)$ years (Table 1$)$.

Seventy-three percent (with $95 \% \mathrm{CI}=68.04,78.02$ ) of the study participants suffered from CVS.

The symptoms most experienced by the study participants were blurred vision (42.4\%), headache $(23.0 \%)$ and redness (23.0\%; Figure S1).

Table I Sociodemographic characteristics of computer-using bank workers in Gondar city, 20I5, n=304 (n=sample size)

\begin{tabular}{ll}
\hline Variables & Frequency (\%) \\
\hline Age, years & \\
$<25$ & $93(30.6)$ \\
$25-30$ & $141(46.4)$ \\
$>30$ & $70(23.0)$ \\
Sex & \\
Female & $106(34.9)$ \\
Male & $198(65.1)$ \\
Marital status & \\
Single & $181(59.5)$ \\
Married & $120(39.5)$ \\
Divorced & $3(1.0)$ \\
Educational status & \\
Diploma & $41(13.5)$ \\
Degree & $239(78.6)$ \\
Masters and above & $24(7.9)$ \\
\hline
\end{tabular}

In the bivariate analysis, sitting position (crude odds ratio $[\mathrm{COR}]=2.56,95 \% \mathrm{CI}=1.41,4.65)$, viewing distance ( $\mathrm{COR}=2.05,95 \% \mathrm{CI}=1.08,3.91)$, the time taking break while using computer $(\mathrm{COR}=2.05,95 \% \mathrm{CI}=1.20,3.49)$ and using eye glasses $(\mathrm{COR}=3.17,95 \% \mathrm{CI}=1.08,9.27)$ were significantly associated with CVS (Table 2).

Multivariate analysis was used to identify characteristics that were independent factors for CVS. By using a forward stepwise selection method, all variables were entered into a multivariate analysis. According to the multivariate analysis, inappropriate sitting position was 2.33 times (adjusted odds ratio $[\mathrm{AOR}]=2.33,95 \% \mathrm{CI}=1.27,4.28$ ) more likely associated with CVS when compared with appropriate sitting position. Working on computer for more than 20 minutes without taking break was significantly $(\mathrm{AOR}=1.93,95 \% \mathrm{CI}=1.11$, 3.35) associated with CVS when compared with taking break within 20 minutes (Table 3).

\section{Discussion}

This study was aimed to assess the prevalence and identify the associated factors of CVS. From the total of 304 computerusing bank worker study participants, the prevalence of CVS was found to be $73 \%(95 \% \mathrm{CI}=68.04,78.02)$. This is in line with the other studies: $72 \%$ in Ajman, United Arab Emirates, among computer worker university students, ${ }^{15} 73.9 \%$ in São Paulo, Brazil, among computer workers ${ }^{16}$ and $73.9 \%$ in University of Gondar, among secretaries and data processors. ${ }^{12}$ Evidently, this study result was less than the result reported in Malaysia, which was found to be $89 \%,{ }^{17}$ and in Chennai, which was $80.3 \%$, ${ }^{18}$ and the reason may be either due to the study participants in these area being university students using computers for a longer time than bank workers or due to students using computers for a long time without eye break for studying rather than most bank workers taking frequent breaks to give services for customers.

Inappropriate sitting position of bank workers was 2.3 times $(\mathrm{AOR}=2.33,95 \% \mathrm{CI}=1.27,4.28)$ more likely associated with CVS when compared with those having appropriate sitting position. This might be explained by the fact that inappropriate sitting position gives discomfort and stress to the eye, which leads the eye to be more focused and causes the eye muscles more spastic and experience symptoms of CVS; however, in an inappropriate sitting position, bank workers report glare as their major complaint, which they faced during computer use. It can also be justified that eyeand environment-related conditions occur because of inappropriate sitting position, when the viewing demands of the task exceed the visual abilities of the user, leading to inability to focus properly on computer images and experience CVS. ${ }^{8}$ 
Table 2 Bivariate analysis for computer vision syndrome among bank workers in Gondar City, $2015, \mathrm{n}=304$ ( $\mathrm{n}=$ sample size)

\begin{tabular}{|c|c|c|c|c|}
\hline \multirow[t]{2}{*}{ Variables } & \multicolumn{2}{|c|}{ Computer vision syndrome } & \multirow[t]{2}{*}{ COR $(95 \% \mathrm{Cl})$} & \multirow[t]{2}{*}{$p$-value } \\
\hline & Yes & No & & \\
\hline \multicolumn{5}{|l|}{ Sex } \\
\hline Male & 151 & 47 & $1.58(0.94,2.67)$ & 0.083 \\
\hline Female & 71 & 35 & 1.00 & \\
\hline \multicolumn{5}{|l|}{ Age, years } \\
\hline$>30$ & 54 & 16 & $1.24(0.60,2.55)$ & 0.558 \\
\hline $26-30$ & 100 & 41 & $0.89(0.50,1.61)$ & 0.339 \\
\hline$\leq 25$ & 68 & 25 & 1.00 & \\
\hline \multicolumn{5}{|l|}{ Marital status } \\
\hline Married & 91 & 29 & $1.27(0.75,2.14)$ & 0.374 \\
\hline Unmarried & $|3|$ & 53 & 1.00 & \\
\hline \multicolumn{5}{|l|}{ Educational level } \\
\hline Degree and above & 193 & 70 & $\mathrm{I} .14(0.55,2.36)$ & 0.722 \\
\hline Diploma & 29 & 12 & 1.00 & \\
\hline \multicolumn{5}{|l|}{ Sitting position } \\
\hline Not appropriate & 89 & 17 & $2.56(1.41,4.65)$ & 0.002 \\
\hline Appropriate & 133 & 65 & 1.00 & \\
\hline \multicolumn{5}{|l|}{ Viewing distance, $\mathrm{cm}$} \\
\hline$\leq 50$ & 66 & 14 & $2.05(1.08,3.91)$ & 0.028 \\
\hline$>50$ & 156 & 68 & 1.00 & \\
\hline \multicolumn{5}{|l|}{ Top of the computer screen } \\
\hline Below the level of eyes & 54 & 18 & $1.29(0.684,2.42)$ & 0.435 \\
\hline Above the level of eyes & 56 & 16 & $1.50(0.78,2.87)$ & 0.222 \\
\hline At the level of eyes & 112 & 48 & 1.00 & \\
\hline \multicolumn{5}{|c|}{ Duration of computer use, years } \\
\hline$\geq 5$ & 75 & 25 & $1.16(0.67,2.00)$ & 0.587 \\
\hline$<5$ & 147 & 57 & 1.00 & \\
\hline \multicolumn{5}{|c|}{ Time of computer use per day, hours } \\
\hline$>6$ & 170 & 56 & $1.52(0.87,2.66)$ & 0.144 \\
\hline$\leq 6$ & 52 & 26 & 1.00 & \\
\hline \multicolumn{5}{|l|}{ Taking break, minutes } \\
\hline$>20$ & 167 & 49 & $2.05(1.20,3.49)$ & 0.009 \\
\hline$\leq 20$ & 55 & 33 & 1.00 & \\
\hline \multicolumn{5}{|l|}{ Eye glass } \\
\hline Using eye glasses & 31 & 4 & $3.17(1.08,9.27)$ & $<0.001$ \\
\hline Not using eye glasses & 191 & 78 & 1.00 & \\
\hline \multicolumn{5}{|l|}{ Frequent voluntary blinking } \\
\hline Yes & 67 & 22 & 1.00 & 0.569 \\
\hline No & 155 & 60 & $1.18(0.67,2.08)$ & \\
\hline \multicolumn{5}{|c|}{ Adjusting computer brightness } \\
\hline Yes & 91 & 32 & 1.00 & 0.757 \\
\hline No & $|3|$ & 50 & $1.09(0.65,1.82)$ & \\
\hline \multicolumn{5}{|l|}{ Glare on the display } \\
\hline Yes & 82 & 23 & $\mathrm{I} .50(0.86,2.6 \mathrm{I})$ & 0.149 \\
\hline No & 140 & 59 & 1.00 & \\
\hline \multicolumn{5}{|l|}{ Using antiglare } \\
\hline Yes & 69 & 22 & 1.00 & 0.473 \\
\hline No & 153 & 60 & $1.23(0.70,2.16)$ & \\
\hline \multicolumn{5}{|l|}{ Any systemic disease } \\
\hline Yes & 18 & 5 & $1.36(0.49,3.79)$ & 0.558 \\
\hline No & 204 & 77 & 1.00 & \\
\hline
\end{tabular}

Abbreviations: $\mathrm{Cl}$, confidence interval; $\mathrm{COR}$, crude odds ratio.

Those working on computer for more than 20 minutes without break were nearly 2 times ( $\mathrm{AOR}=1.93,95 \% \mathrm{CI}=1.11$, 3.35) more likely to suffer from CVS as compared to those taking break within 20 minutes. This was similar to the study done in the suburban area of Chennai and in Uttar Pradesh, India, in which significant correlation was found between taking less frequent breaks or working on computer for more than 20 minutes without break and being more exposed for 
Table 3 Multivariate analysis for computer vision syndrome among bank workers in Gondar City, 20I5, n=304 ( $\mathrm{n=sample} \mathrm{size)}$

\begin{tabular}{|c|c|c|c|c|c|}
\hline \multirow[t]{2}{*}{ Variables } & \multicolumn{3}{|c|}{ Computer vision syndrome } & \multirow[t]{2}{*}{ AOR $(95 \% \mathrm{Cl})$} & \multirow[t]{2}{*}{ p-value } \\
\hline & $\overline{\text { Yes }}$ & No & COR $(95 \% \mathrm{Cl})$ & & \\
\hline \multicolumn{6}{|l|}{ Sitting position } \\
\hline Not appropriate & 89 & 17 & $2.56(I .41,4.65)$ & $2.33(1.27,4.28)$ & 0.006 \\
\hline Appropriate & 133 & 65 & 1.00 & 1.00 & \\
\hline \multicolumn{6}{|l|}{ Taking break, minutes } \\
\hline$>20$ & 167 & 49 & $2.05(1.20,3.49)$ & $1.93(1.11,3.35)$ & 0.020 \\
\hline$\leq 20$ & 55 & 33 & 1.00 & 1.00 & \\
\hline \multicolumn{6}{|l|}{ Eye glass } \\
\hline Using eye glasses & 31 & 4 & $3.17(1.08,9.27)$ & $3.19(1.07,9.51)$ & 0.038 \\
\hline Not using eye glasses & 191 & 78 & & 1.00 & \\
\hline
\end{tabular}

Abbreviations: $\mathrm{AOR}$, adjusted odds ratio; $\mathrm{Cl}$, confidence interval; $\mathrm{COR}$, crude odds ratio; $\mathrm{n}$, sample size.

symptoms of CVS when compared with taking more frequent breaks within 20 minutes. ${ }^{18,19}$ These bank workers who had not been taking break within 20 minutes suffered from CVS more significantly, because the eyes normally cannot remain focused on the pixel-generated images on a computer screen for a long time, and as such, the eyes must focus and refocus thousands of times by taking frequent breaks (high refresh rate that the computer screen is repainted to produce an image) within 20 minutes while viewing the screen, and if the refresh rate is too slow it causes a high flickering screen, which leads to suffer from symptoms of CVS. ${ }^{8}$

Bank workers who wore eye glasses were 3 times (AOR=3.19, 95\% CI=1.07, 9.51) more likely exposed for CVS when compared with those not wearing eye glasses. Similar results were reported in Malaysia, where computer users who were wearing spectacles experienced CVS significantly more often than those who were not wearing spectacles. ${ }^{17}$ Justification for higher prevalence of CVS among eye glass wearers might be that spectacles were not been prescribed by professionals, which resulted in either incorrect prescription or absence of glare or reflection protection surfaces.

\section{Conclusion}

About three-fourths of computer-using bank workers suffered from CVS with the most experienced symptoms of blurred vision, headache and redness of eyes. Inappropriate sitting position, working on the computer for more than 20 minutes without taking frequent breaks and wearing eye glasses were the factors independently associated with CVS. To avoid these computer-related vision problems, it is better to give eye health education for computer users on how to use computers, and the symptoms, treatment options and prevention strategies of CVS.

\section{Acknowledgments}

We were grateful to appreciate University of Gondar for the financial support that enabled us to conduct the study. We would also like to give our deepest gratitude to the study participants for their kindness and cooperation to be included in the study.

\section{Author contributions}

All authors contributed toward data collection, data analysis, drafting and critically revising the paper and agree to be accountable for all aspects of the work.

\section{Disclosure}

The authors report no conflicts of interest in this work.

\section{References}

1. Griffiths KL, Mackey MG, Adamson BJ. The impact of a computerized work environment on professional occupational groups and behavioral and physiological risk factors for musculoskeletal symptoms. J Occup Rehabilx. 2007;17(4):743-765.

2. Anshel J, editor. Visual Ergonomics Handbook. New York, NY: Taylor and Francis; 2005

3. Sen. A, Richardson S. A study of computer-related upper limb discomfort and computer vision syndrome. J Hum Ergol (Tokyo). 2007;36(2): 45-50.

4. Bali J, Navin N, Thakur BR. Computer vision syndrome: a study of the knowledge, attitudes and practices in Indian ophthalmologists. Indian J Ophthalmol. 2007;55(4):289-294.

5. Computer vision syndrome (CVS). American Optometric Association [cited April 14, 2012]. Available from: http://www.aoa.org/x5374.xml. Accessed March 11, 2015.

6. Grand AH. The computer user syndrome. J Am Optom Assoc. 1987; 58(11):892-901.

7. Kozeis N. Impact of computer use on children's vision. Hippokratia. 2009;13(4):230-231.

8. Charpe NA, Kaushik V. Computer vision syndrome (CVS): recognition and control in software professionals. J Hum Ecol. 2009;28(1): 67-69.

9. Hayes JR, Sheedy JE, Stelmack JA, Heaney CA. Computer use, symptoms, and quality of life. Optom Vis Sci. 2007;84(8):738-744. 
10. Nunoo M. A sight for sore eyes: Computer displays can be hazardous to your vision. Black enterprise. 1996;28(3):44-45.

11. Yallew WW, Terefe MW, Herchline TE, et al. Assessment of water, sanitation, and hygiene practice and associated factors among people living with HIV/AIDS home based care services in Gondar city, Ethiopia. BMC Public Health. 2012;12:1057.

12. Alemayehu M, Nega A, Tegegne E, Mule Y. Prevalence of self reported computer vision syndrome and associated factors among secretaries and data processors. J Biol Agric Healthc. 2014;4(15):2224-3208.

13. Hazarika AK, Singh PK. Underlying eye conditions responsible for computer vision syndrome. SMU Med J. 2014;1(2):132-138.

14. Stella C, Chiemeke Member, IAENG, Allen E, Akhahowa, Olajire B. Evaluation of Vision-Related Problems amongst Computer Users: A Case Study of University of Benin, Nigeria. Proceedings of the World Congress on Engineering WCE 2007 Vol 1, London, UK, 2-4 July 2007.
15. Shantakumari N, Eldeeb R, Sreedharan J, Gopal K. Computer use and vision-related problems among university students in ajman, United Arab Emirate. Ann Med Health Sci Res. 2014;4(2):258-263.

16. Sá E, Rocha L. The prevalence of risk factors associated with computer vision syndrome among computer works in São Paulo, Brazil. Occup Environ Med. 2014;71 (Suppl 1):A103.

17. Reddy SC, Low CK, Lim YP, Low LL, Mardina F, Nursaleha MP. Computer vision syndrome: a study of knowledge and practices in university students. Nepal J Ophthalmol 2013;5(10):161-168.

18. Logaraj M, Madhupriya V, Hegde S. Computer vision syndrome and associated factors among medical and engineering students in Chennai. Ann Med Health Sci Res. 2014;4(2):179-185.

19. Agarwal S, Goel D, Sharma A. To evaluate the factors contributing to Ocular complaints in computer users. J Clin Diagn Res. 2013;7(2): 331-335. 


\section{Supplementary material}

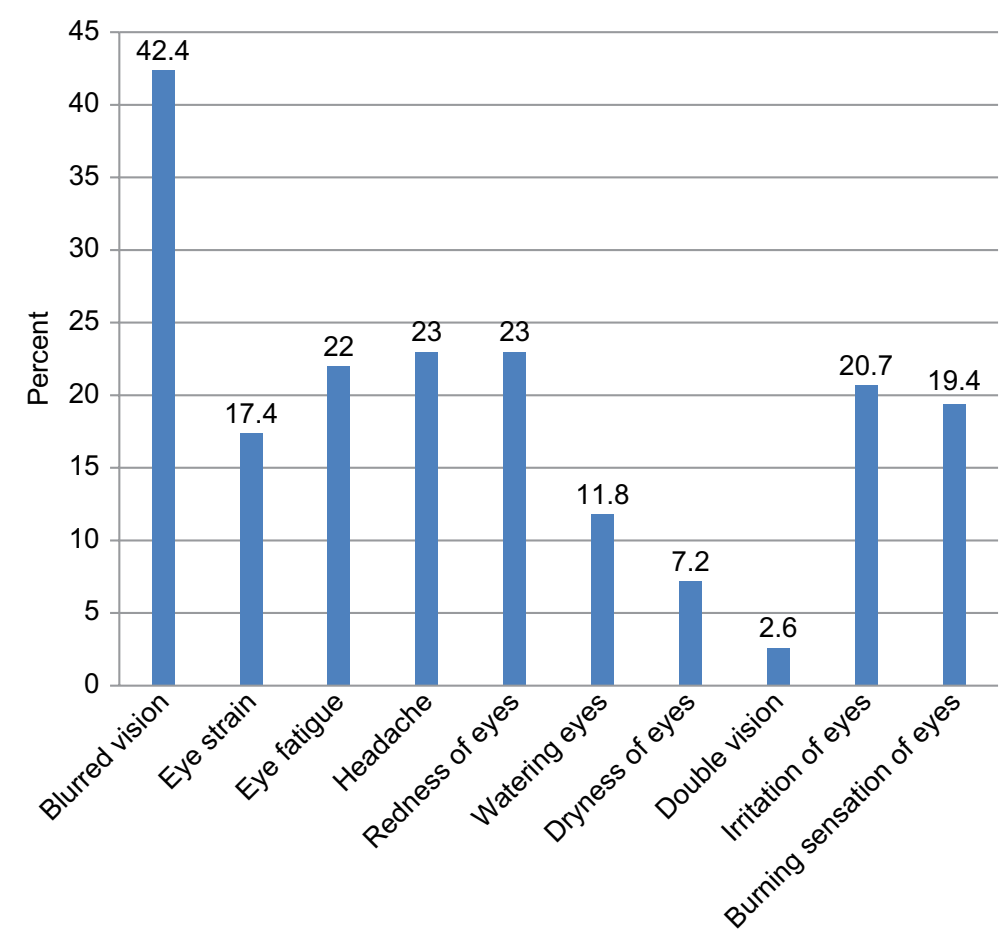

Symptoms of computer vision syndrome

Figure SI Prevalence of symptoms of computer vision syndrome among bank workers in Gondar city, 20I5, n=304.

\section{UNIVERSITY OF GONDAR COLLEGE OF MEDICINE AND HEALTH SCIENCES DEPARTMENT OF OPTOMETRY}

Face-to-face interview questionnaire for assessment of prevalence and risk factors of computer vision syndrome among bank workers in Gondar city.

Questionnaire identification number

Name of bank

Verbal consent form:

Hello, my name is working in university of Gondar, Department of Optometry. Today I am here to ask you few questions related to the computer use.

The study will involve various intimate and computer use-related questions. In order to effectively attain the objective of the research, your patience will take the lead. There are questions that you are expected to answer related to personal and environmental factors associated with computer vision syndrome and there is no need to tell your name. No individual responses will be reported. Your responses will be completely confidential. It is your full right to refuse in responding any question or all of the questions. However, your honest answers to these questions will help us in better understanding of magnitude and associated factors of computer vision syndrome. So, I kindly request you to give your honest responses and your participation. It will take a maximum of 10 minutes to answer these questions. 
1. If yes, continue to the next page

2. If no, continue to the next participant by writing the reasons for refusal.

Part I: Sociodemographic data

1. Age

2. Sex

Female

Male

3. Marital status

$\square$ Single

$\square$ Married

$\square$ Divorced

Widowed

4. Educational status

$\square$ Certificate

Diploma

$\square$ Degree

Master and above

Part II. Have you experienced any one of the following symptoms while using/after finishing the work on computer? (May have more than one symptom, encircle it)

\section{Blurred vision}

Eye strain

$\square$ Eye fatigue

Headache

Redness of eyes

Watery eyes

Dryness of eyes

Double vision

Eye irritation

Burning sensation

Part III. Personal factors

1. Seating position

Appropriate/The face of the operator just in level to the computer screen

$\square$ Inappropriate

2. Viewing distances

$\square$ Less than or equal to $50 \mathrm{~cm}$

$\square$ Greater than $50 \mathrm{~cm}$

3. Level of top of the computer screen

$\square$ Above the level of eyes

$\square$ At the level of eyes

Below the level of eyes

4. Duration of computer use (years)

$<5$

$\square 5-10$

$\square>10$ 
5. Working time on computer per day (hours/day)
$\square<3$
$\square 3-6$
$\square>6$

6. Do you have a habit of taking break while using computer?
$\square$ Yes
$\square$ No

7. If the answer for question no. 6 is yes, by how much minute after work?
$\square<20$ minutes
$\square>20$ minutes

8. Do you use eye glass?
$\square$ Yes
$\square$ No

9. If the answer for question no.7 is yes, what is the purpose of the glass?
$\square$ For computer use
$\square$ For vision
$\square$ For other purpose

10. Do you have a habit of frequent voluntary blinking?
$\square$ Yes
$\square$ No

11. Do you have any systemic disorders?
$\square$ yes

$\square$ No

12. If yes for No. 10 specify disease

Part IV. Computer and environmental variables

1. Do you adjust the contrast of your computer with the surrounding brightness?

$\square$ Yes
$\square$ No

2. Is any glare on the computer screen?
$\square$ Yes
$\square$ No

3. Do you use antiglare for your computer screen?
$\square$ Yes
$\square$ No

Name and signature of data collector

Date of interview

Checked by supervisor

Name and signature

Figure S2 English version of questionnaire. 


\section{Publish your work in this journal}

Clinical Optometry is an international, peer-reviewed, open access journa publishing original research, basic science, clinical and epidemiological studies, reviews and evaluations on clinical optometry. All aspects of patient care are addressed within the journal as well as the practice of optometry including economic and business analyses. Basic and clinical

Submit your manuscript here: https://www.dovepress.com/clinical-optometry-journal research papers are published that cover all aspects of optics, refraction and its application to the theory and practice of optometry. The manuscript management system is completely online and includes a very quick and fair peer-review system, which is all easy to use. Visit http://www.dovepress. com/testimonials.php to read real quotes from published authors. 